\title{
Electrochemical Behavior of Pt(IV) on Mercury Electrode in the Presence of Dimethylglyoxime
}

\author{
M. Georgieva * \\ Institute of Chemistry, Faculty of Science, St. Cyril \& Methodius University, \\ Skopje, Republic of Macedonia
}

Received 22 May 2002; Accepted in revised form 26 October 2002

\begin{abstract}
The electrochemical behavior of Pt(IV) ions in the presence of dimethylglyoxime has been investigated using adsorptive stripping voltammetric method. The results indicated that the platinum is reduced from its adsorbed state as bis-dimethylglyoxi-mate platinum(IV) complex. The peak current is linearly proportional to the $\mathrm{Pt}(\mathrm{IV})$ concentration in the solution, thus representing the basis for a quantitative analysis. Various experimental parameters affecting the stripping response, indicating $\mathrm{pH}$, the ligand concentration or the accumulation time and potential, and the scan rate, were studied to obtain a highly linear response. From the results the scheme for the reduction process of the platinum dimethylglyoximate complex in acidic media is presented.
\end{abstract}

Keywords: reduction process, platinum, adsorptive stripping voltammetry, dime-thylglyoxime.

\section{Introduction}

The platinum group metals (PGM) have an excellent performance in many catalytic processes used for obtaining minimal release of pollutants into the environment [1-2].

The ability of the PGM to form many species in a given oxidation state, their tendency to hydrolyse and the formation of polynuclear complexes make determination, especially at low concentration levels, very difficult. Complete dissolution of the PGM, quantitative conversion into suitable complexes and their preconcentration before final detection are critical steps in almost all analytical procedure [3].

Since the concentration of PGM is extremely low in various samples, a sufficiently sensitive method for their reliable determination would be of great interest. The more

\footnotetext{
* Corresponding author. E-mail address: marijage@hotmail.com
} 
popular voltammetric method following adsorptive accumulation of the metal chelates is becoming a widely accepted analytical tool. Many electrochemical active complexes of PGM can be adsorbed on the mercury electrode surface to cause a catalytic hydrogen current. Mostly based on this principle, several electroanalytical methods for the trace determination of PGM have been reported in the last few years [4-13]. Various supporting electrolytes, different complexing ligands, and corresponding detection limits for the determination of platinum were reviewed [14].

In our previous investigations dimethylglyoxime (DMG) [15-16] and other oximes [17] were used for the adsorptive preconcentration of palladium on the stationary mercury electrode. From the analytical point of view these studies agree with the data published by Wang and Varughese [18]. The present study is intended to examine the utility of adsorptive stripping voltammetric procedure for platinum(IV), based on the reduction of the adsorbed platinum-dimethylglyoximate complex (Pt-DMG) in acidic media.

\section{Experimental}

Voltammetric measurement were performed with an EG\&G PAR model 264A stripping voltammeter in connection to the EG\&G 303 stationary mercury electrode (SMDE). An $\mathrm{Ag} / \mathrm{AgCl}$ electrode filled with a saturated $\mathrm{KCl}$ solution was used as a reference electrode and a platinum wire as an auxiliary. The voltammograms were recorded on an Omnigraphic 100 X-Y recorder Model RE 0089.

All reagents were of analytical reagent grade. Deionized water was additionally purified using the Milli - Q system. Acetate buffer of $\mathrm{pH} 4.6$ was used as a supporting electrolyte. This was prepared by mixing the appropriate amounts of $0.1 \mathrm{M}$ acetic acid and 0.1 M sodium acetate. A stock solution of 0.1 M DMG (butane-2,3 dione dioxime, Merck) was prepared by dissolution of the pure substance in absolute ethanol.

A platinum standard stock solution $(1.00 \mathrm{mg} / \mathrm{mL})$ was prepared by dissolving platinum wire $(99.99 \%)$ in aqua regia. The solution obtained was evaporated almost to dryness.

Conc. $\mathrm{HCl}(5 \mathrm{~mL})$ was added and the solution was evaporated to a small volume. The residue was then dissolved in a few drops of $1 \mathrm{M} \mathrm{HCl}$ and the solution obtained was diluted to $50 \mathrm{~mL}$ with $0.1 \mathrm{M} \mathrm{HCl}$. The platinum(IV) solution was standardized gravimetrically (precipitation with DMG). Working standards were prepared by serial dilution with $0.1 \mathrm{M} \mathrm{HCl}$. A combined glass electrode and a $\mathrm{pH}$ meter were used for the pH measurement. 
Ten milliliters of supporting electrolyte solution (acetate buffer, $\mathrm{pH}=4.6$ ) and $1 \times 10^{-4} \mathrm{M}$ DMG was pipetted into the cell and oxygen was removed by purging with pure argon (99.9\%) for $4 \mathrm{~min}$. After that, adsorption was carried out of the stirred solution for a period of $120 \mathrm{~s}$ at medium drop size $\left(0.029 \mathrm{~cm}^{2}\right)$. Following the accumulation period, the stirring was stopped and after $15 \mathrm{~s}$ of equilibration the voltammogram was recorded at $-0.4 \mathrm{~V}$. Measurements were made by applying a differential pulse (DPP) mode with scan rate of $10 \mathrm{mV} / \mathrm{s}$ in the negative (cathodic) direction. After recording the background voltammogram, an aliquot of the metal standard solution was introduced in the cell, and the accumulation-stripping cycle was repeated. All data were obtained at room temperature.

\section{Results and Discussion}

In order to obtain some information and additional support on the adsorption of the platinum chelate on the stationary mercury electrode voltammetric measurements were investigated. As it is evident from the voltammograms shown in Fig. 1, the reduction of platinum(IV) in the presence of DMG is a totally irreversible process which appears at a potential about $120 \mathrm{mV}$ more positive than the reduction of the ligand itself.

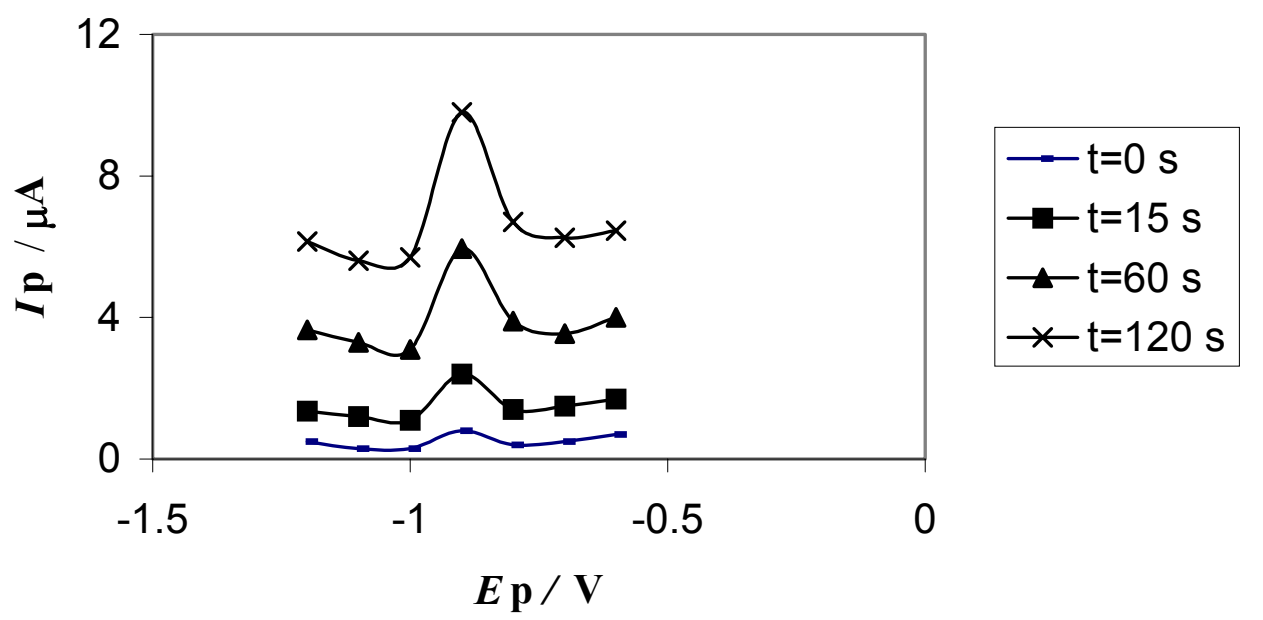

Figure 1. Voltammetric curves in $0.1 \mathrm{M}$ acetate buffer at $\mathrm{pH} 4.6 ; 1 \times 10^{-4} \mathrm{M} \mathrm{DMG}+15$ $\mu \mathrm{g}$ Pt/L; deposition times: - - $0 \mathrm{~s}$, $\square-15 \mathrm{~s}, \boldsymbol{\Delta}-60 \mathrm{~s}, \times-120 \mathrm{~s}$ at $-0.4 \mathrm{~V}$; electrode area: $0.028 \mathrm{~cm}^{2}$.

The reduction of the DMG ligand appears at much more negative values $(\mathrm{Ep}=-1.055$ V). It is observed that the peak height associated with the reduction of Pt-DMG complex is highly dependent on the preconcentration time at constant initial potential. 
At the same time the peak height is very reproducible. This fact excludes any pathway on the accumulation of some radicals at the electrode surface. On the other hand, the asymmetrical shape of the peak, supports the assumption that the reduction of platinum(IV) in the presence of DMG involves adsorption of the reactant on the surface of the mercury electrode. However, small amount of surfactants such as Triton X-100 and other strongly suppressed the peak height. These two phenomena indicated that the platinum complex is strongly adsorbed on the mercury electrode surface. In this way, highly sensitive measurements of the platinum chelate can be achieved by using the method of adsorptive stripping voltammetry (AdSV).

The strong and often linear dependence of the metal-ligand current signal upon the metal concentration, inspired us to explore the feasibility of using various experimental parameters affecting the stripping response of the complex, such as $\mathrm{pH}$, reactant concentrations, accumulation time and potential and scan rate. These parameters were studied in detail.

Preliminary experiments were carried out with different types of buffers such as hydrogen chloride, acetate, phosphate and ammonium buffer. The results showed that the voltammetric peak height was improved in the presence of acetate buffer. Thus, for voltammetric measurements a solution of acetic acid and sodium acetate was used as the optimal buffer solution. Fig. 2 shows the dependence of peak potential and peak current of the Pt-DMG complex on $\mathrm{pH}$ in the acetate buffer. The position of the peak depends on the $\mathrm{pH}$ values. It is shifted as shown in the same figure by approximately $90 \mathrm{mV}$ in a cathodic direction with a ten-fold decrease in the hydrogen ion concentration. The peak current remains constant in the range $\mathrm{pH} 3$ to 4 . Then, it starts to increase, reaches a maximum at $\mathrm{pH} 4.6$ and decreases at higher $\mathrm{pH}$ values, becoming practically negligible at even slightly alkaline media. The decrease of the peak current with an increase in $\mathrm{pH}$, is probably due to the diminished complexing ability of the ligand at such greater $\mathrm{pH}$ values. On the other hand, at higher $\mathrm{pH}$ values, it was expected the small apparent formation constant of the chelate at these $\mathrm{pH}$ values. Therefore, a $\mathrm{pH}$ of 4.6 seems to be most suitable for further studies. To check participation of hydrogen ions in the rate determining step (rds) of the electrode process, the experiments were repeated in the 0.1 $\mathrm{M}$ phthalate buffer. It was found that the shift in peak potential is approximately 100 $\mathrm{mV}$ per unit increment of $\mathrm{pH}$. It is also linearly dependent on $\mathrm{pH}$ between 4.0 and 6.0. The dependence of the peak potential on the $\mathrm{pH}$ of the media confirms the influence of 
the hydrogen ion on the reaction rate. $I_{\mathrm{p}}-\mathrm{pH}$ dependence expressed a similar profile as in the acetate buffer, but with a maximum peak height around $\mathrm{pH} 4.4$.

A

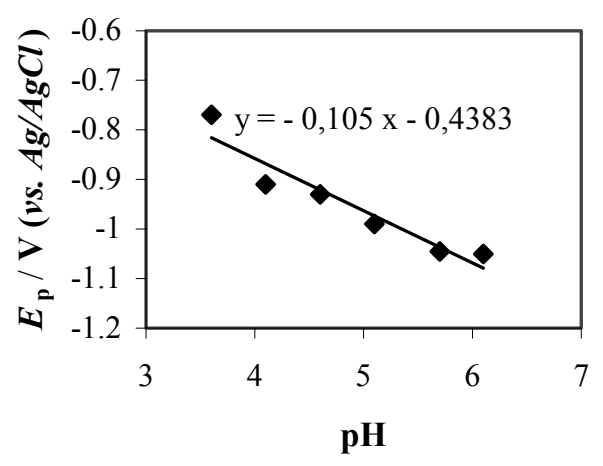

B

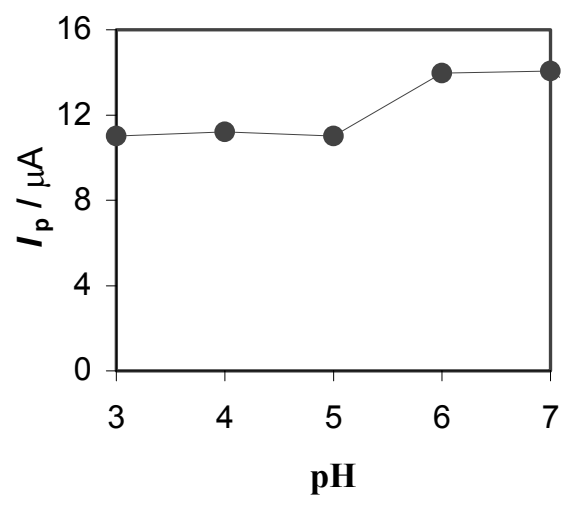

Figure 2. Dependence of the peak current (A) and peak potential (B) on $\mathrm{pH}$ in $0.1 \mathrm{M}$ acetate buffer, $1 \times 10^{-4} \mathrm{M} \mathrm{DMG}+15 \mu \mathrm{g} \mathrm{Pt} / \mathrm{L}$; deposition time: $2 \mathrm{~min}$ at $-0.4 \mathrm{~V}$, electrode area: $0.028 \mathrm{~cm}^{2}$.

The ligand concentration in solution has a profound effect on the voltammetric peak height. By increasing the ligand concentration from $1 \times 10^{-5} \mathrm{M}$ to $1 \times 10^{-4} \mathrm{M}$, the voltammetric peak height increases, showing, as expected, that its height is strongly dependent upon the ligand concentration. For concentrations higher than of $3 \times 10^{-4} \mathrm{M}$ a significant decrease in the peak height was observed. This effect may be due to the competitive adsorption of free $\mathrm{H}_{2} \mathrm{D}$ [15], with the complex form. The effect of the ligand concentration on peak height in an acetate buffer of $\mathrm{pH} 4.6$ at different platinum concentration is shown in Fig. 3. As it can be seen the concentration of $1 \times 10^{-4} \mathrm{M} \mathrm{DMG}$, at $\mathrm{pH} 4.6$ and a preconcentration time of 2 minutes, gives a linear response at a platinum 
concentration below $10 \mu \mathrm{g} / \mathrm{L}$. At higher concentration of platinum a shorter preconcentration time and an accumulation in the nonstirred solutions should be used to obtain the linear response.

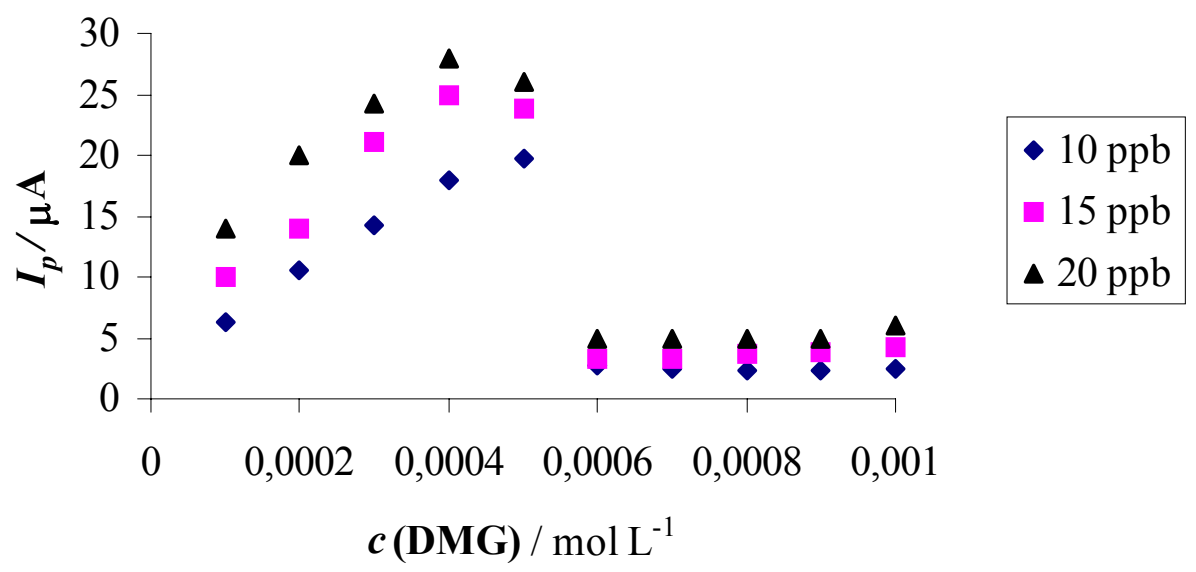

Figure 3. Effect of the DMG concentration on peak height in an acetate buffer of $\mathrm{pH}$ 4.6 at different concentration of platinum: $\diamond-10 \mu \mathrm{g} \mathrm{Pt} / \mathrm{L}, \boldsymbol{\square}-15 \mu \mathrm{g} \mathrm{Pt} / \mathrm{L}, \boldsymbol{\Delta}-20 \mu \mathrm{g}$ $\mathrm{Pt} / \mathrm{L}$; deposition time: $2 \mathrm{~min}$ at $-0.4 \mathrm{~V}$, electrode area: $0.028 \mathrm{~cm}^{2}$.

The extent of preconcentration depends on the length of time over which the adsorption is allowed to proceed. The dependence of the platinum stripping peak current on the preconcentration time was studied with solution of various platinum(IV) concentrations and the results are shown in Fig. 4. For a lower concentration of platinum, the peak current increases rapidly with increasing preconcentration time from 0 to $70 \mathrm{~s}$, and levels off for longer periods. For higher concentration of platinum the peak current increases as the preconcentration time increases and starts to level off around $240 \mathrm{~s}$. Such timedependent profile reflects the enhancement of the surface concentration of the Pt-DMG complex. Short accumulation times are sufficient for obtaining a substantial signal enhancement, and a well-defined response. In consequence, a $60 \mathrm{~s}$ accumulation yielded about 7-fold enhancement of the peak, to that obtained without preconcentration, respectively.

The effect of the accumulation potential on the stripping peak current of the platinum complex was examined over the potentials range of +0.1 to $-0.6 \mathrm{~V}$. As shown in Fig.5 (curve $\diamond$ ) the Pt-DMG complex is adsorbed over a wide potential range from +0.1 to $0.6 \mathrm{~V}$ with a slight variation in the response. As expected, at more positive potential, the adsorption of the complex is inhibited, due to electrode surface oxidation. At more negative potential than $-0.6 \mathrm{~V}$, the peak current decreases. This can be explained by 
the instantaneous reduction of the complex at this potential. Therefore, an optimal accumulation potential between 0 and $-.0 .6 \mathrm{~V}$ should be used in subsequent work. The presence of the nonionic surfactant Triton X-100 has a severe effect on the peak height (curves $\mathbf{\square}, \mathbf{\Delta}$ ). Its effect becomes more pronounced as the potential of zero charge (pzc) [15] is approached. The peak heights decreased to $30 \%$ of the initial value when 0.1 $\mathrm{mg} / \mathrm{L}$ of Triton X-100 was added to the solution, and were completely suppressed with addition of $1 \mathrm{mg} / \mathrm{L}$ Triton X-100.

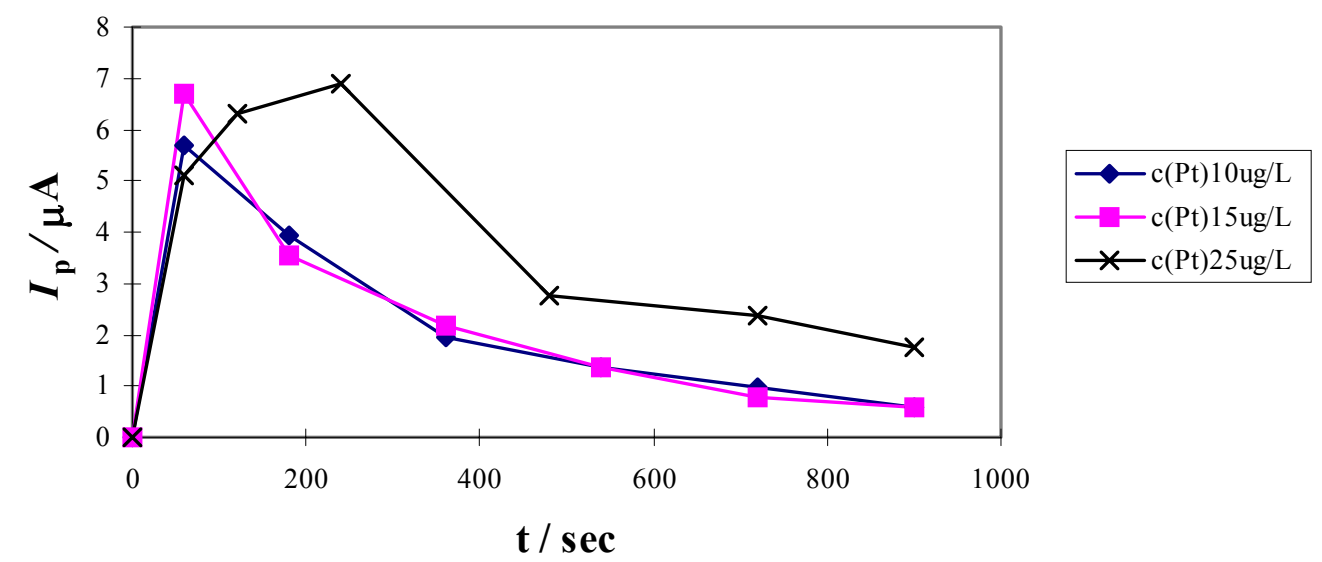

Figure 4. Effect of the DMG concentration on peak height in an acetate buffer of $\mathrm{pH}$ 4.6 at different concentration of platinum: $\downarrow-10 \mu \mathrm{g} \mathrm{Pt} / \mathrm{L}, \mathbf{\square}-15 \mu \mathrm{g} \mathrm{Pt} / \mathrm{L},+-20 \mu \mathrm{g}$ $\mathrm{Pt} / \mathrm{L}$; deposition time: $2 \mathrm{~min}$ at $-0.4 \mathrm{~V}$, electrode area: $0.028 \mathrm{~cm}^{2}$.

Other condition that affects the adsorptive response of the complex is the scan rate. The influence of the scan rate on the peak current of the complex was examined over the range $1.0-30.0 \mathrm{mV} / \mathrm{s}$. The peak height increases slightly at first up to $10 \mathrm{mV} / \mathrm{s} \mathrm{(Fig.} \mathrm{6A)}$ and then decreases for greater values of the scan rate. The reduction current of adsorbed complex ions increases linearly with the scan rate [19-20] because a constant amount of adsorbed species is reduced in a shortened time span, unless the reduction efficiency diminishes at high scan rate. However, in this case, a non-linear increase of the peak height was observed as a result of hydrogen formation at high scan rates. It was found that the peak potential is shifted to more negative potentials with increasing scan rate $v$ (Fig. 6B or 6C). The shift of the peak potential with the scan rate indicates some irreversibility of the redox process of the adsorbed reactants on the electrode [21-22] and an effective interfacial accumulation of the platinum chelate. 


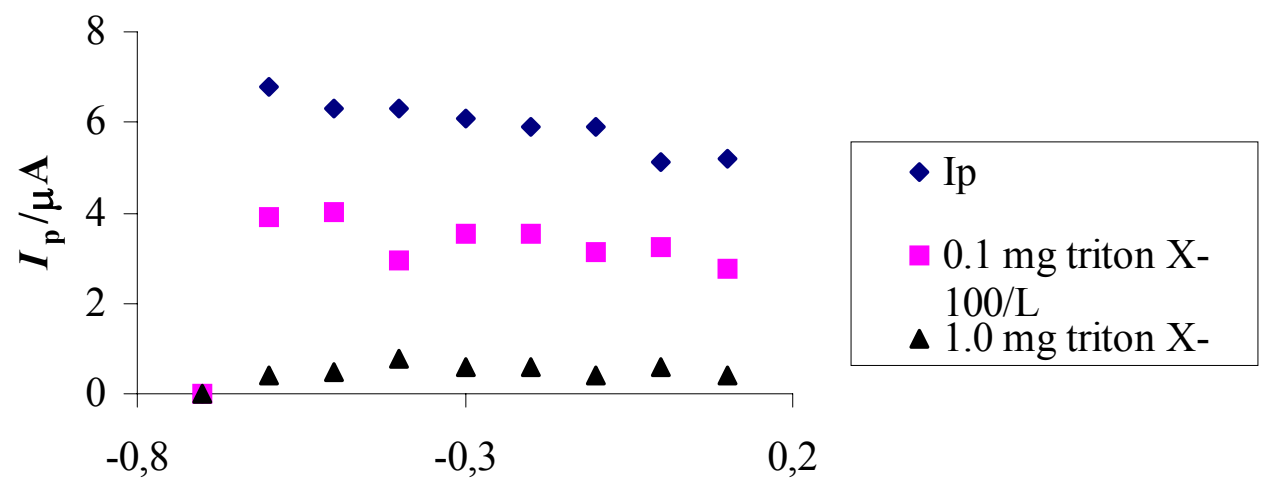

$\mathrm{Ep} / \mathrm{V}(\mathrm{vs} . \mathrm{Ag} / \mathrm{AgCl})$

Figure 5. Peak current dependence on the accumulation potential $(\diamond)$ at different concentrations of Triton X-100: $0.1 \mathrm{M}$ acetate buffer of $\mathrm{pH} 4.6,1 \times 10^{-4} \mathrm{M} \mathrm{DMG}+15 \mu \mathrm{g}$ $\mathrm{Pt} / \mathrm{L}$; $\mathbf{\square}-0.1 \mathrm{mg}$ Triton X -100/L, $\boldsymbol{\Delta}$ - $1.0 \mathrm{mg}$ Triton X - 100/L; deposition time 2 min; electrode area: $0.028 \mathrm{~cm}^{2}$.

\section{Reaction mechanism}

The mechanism of the electrode process is difficult to define in detail, but the properties reported provide some evidence about the reduction of platinum(IV) in the presence of DMG.

In the absence of DMG, the $\left[\mathrm{PtCl}_{6}\right]^{2-}$ complexes are known [23] to be highly inert stable species. In the presence of DMG, dynamic equilibrium between the main species in solution prevails:

$$
\left[\mathrm{PtCl}_{6}\right]^{2-}+2 \mathrm{H}_{2} \mathrm{D} \leftrightarrows\left[\mathrm{Pt}(\mathrm{HD})_{2}\right]^{2+}+2 \mathrm{H}^{+}+6 \mathrm{Cl}^{-}
$$

$\mathrm{H}_{2} \mathrm{D}$ represents the undissociated DMG ligand $\left(K_{\mathrm{a}}=10^{-10,5}\right.$ [24]) and $\mathrm{HD}^{-}$its dissociated form which enters into the chelate. Under the conditions used throughout the experiments, the equilibrium represented by eq. (1) is far to the right, i.e. platinum is chelated quantitatively by DMG.

The adsorption of $\left[\mathrm{Pt}(\mathrm{HD})_{2}\right]^{2+}$ on the mercury electrode proceeds in this medium only if an external potential is applied. Its extent is practically constant over a wide range of potentials. The adsorptive equilibrium can be described by the following equation:

$$
\left.\left[\mathrm{Pt}(\mathrm{HD})_{2}\right]^{2+}(\mathrm{aq}) \stackrel{\leftrightarrows}{\leftrightarrows} \mathrm{Pt}(\mathrm{HD})_{2}\right]^{2+}(\mathrm{ads})
$$


A

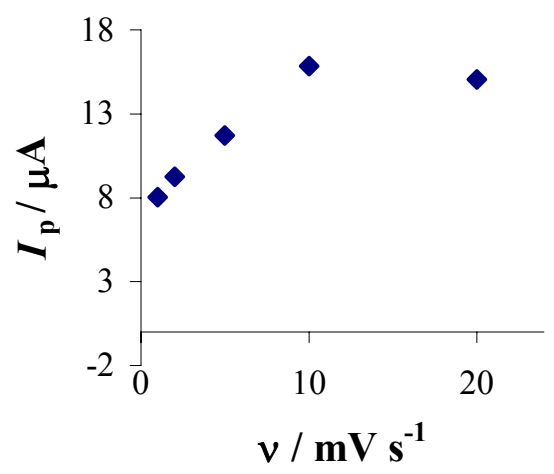

B

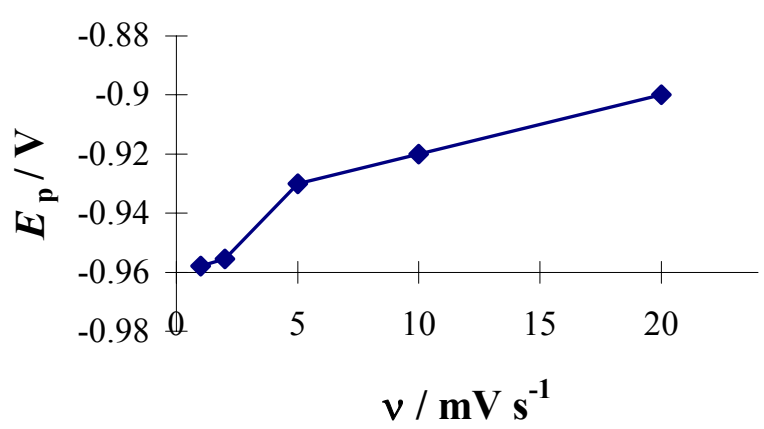

C

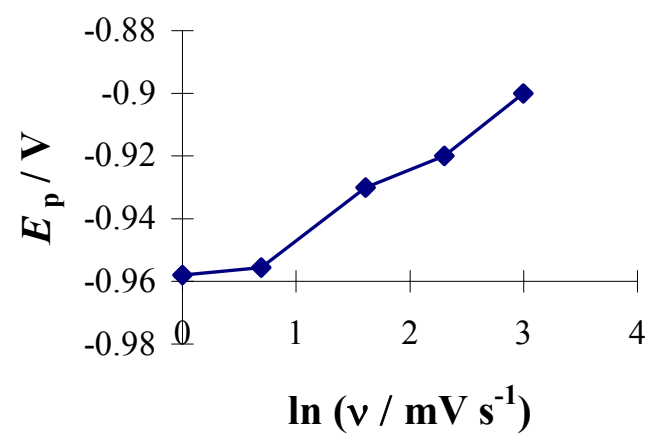

D

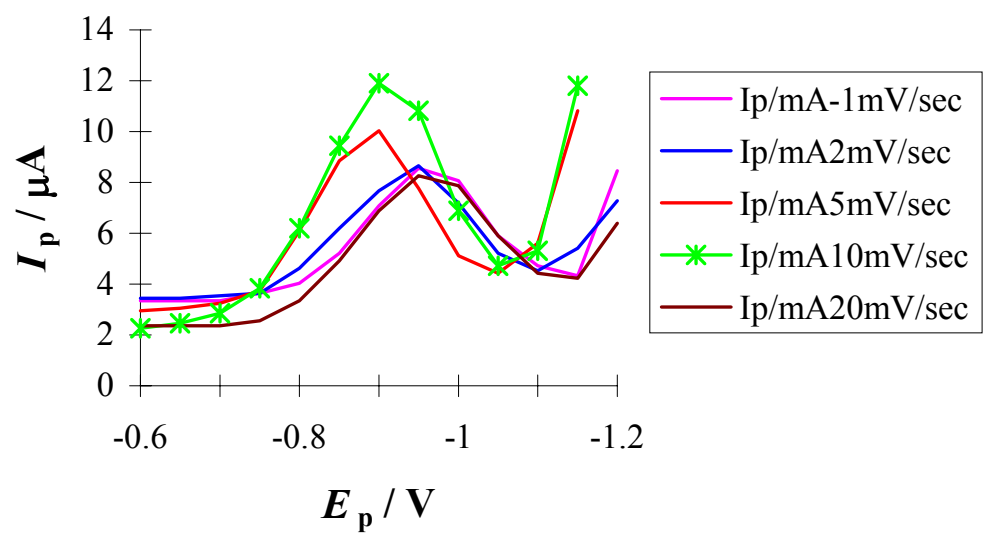

Figure 6. Dependence of the peak current (A), peak potential $(\mathbf{B})$, and $(\mathbf{C})$, on the scan rate in $0.1 \mathrm{M}$ acetate buffer of $\mathrm{pH} 4.6,1 \times 10^{-4} \mathrm{M} \mathrm{DMG}+15 \mu \mathrm{g} \mathrm{Pt} / \mathrm{L}$; deposition time: 2 min at $-0.4 \mathrm{~V}$; electrode area: $0.028 \mathrm{~cm}^{2}$. 
As such positive potentials the adsorption of the platinum chelate is inhibited. It is particularly hindered when nonionic surfactants and adsorbable anions are present [15]. Therefore, to collect any significant amount of the chelate at the electrode surface, an external potential more negative than $-0.2 \mathrm{~V}$ must be applied.

We propose that the platinum chelate is reduced to a low oxidation state. The reduction is described by the following overall equation:

$$
\left[\mathrm{Pt}(\mathrm{HD})_{2}\right]^{2+}{ }_{(\mathrm{ads})}+\mathrm{Hg}+2 \mathrm{H}^{+}+4 \mathrm{e}^{-} \leftrightarrows \mathrm{Pt}(\mathrm{Hg})+2 \mathrm{H}_{2} \mathrm{D}_{(\mathrm{des})}
$$

\section{Conclusions}

From the investigation of the experimental parameters affecting the electrode process rate it was found that a possible mechanism for the overall electrode process in adsorption voltammetry of the Pt-DMG system can be divided into three steps. These are the dynamic equilibrium between dimethylglyoximato species in solution, the adsorption of $\left[\mathrm{Pt}(\mathrm{HD})_{2}\right]^{2+}$ on the $\mathrm{Hg}$ electrode, and the irreversible reduction of the adsorbed component. The results of our investigations showed that platinum(IV) is reduced from its adsorbed state. The reduction process is totally irreversible, only in the presence of DMG ligand. The surface concentration of Pt-DMG complex which is adsorbed depends on the concentration of these species in the bulk of solution according to dynamic equilibrium between different platinum species. For analytical application of this method, it is important to ensure an optimum $\mathrm{pH}$ value, DMG concentration, accumulation time and potential and to work with a low electrode surface coverage where $I_{\mathrm{p}}$ shows a linear dependence on $C\left[\operatorname{Pt}(\mathrm{HD})_{2}\right]^{2+}$. The optimization of the differential-pulse operation indicated that a scan rate of $10 \mathrm{mV} / \mathrm{s}$ (Fig. 6D) and a pulse height of $25 \mathrm{mV}$ were the most favorable, since the sensitivity of the adsorptive stripping voltammetric measurements can be increased.

\section{References}

1. G.W. Cordonna, M. Kosanovich, E.R. Becker, Plat. Met. Rev. 33 (1989) 46.

2. F.R. Hartley, Chemistry of the Platinum Group Metals, Elsevier, Amsterdam, 1991 pp. 60-74.

3. C.R.M. Rao, G.S. Reddi, Trends Anal. Chem. 9 (2000) 565.

4. C. Van den Berg, G.S. Jacinto, Anal. Chim. Acta 211 (1998) 129. 
5. K. Hoppstock, F. Alt, K. Cammanu, G. Weber, Fresenius J. Anal. Chem. 335 (1989) 813.

6. O. Nygren, G.T. Vaughan, T.M. Florence, G.M.P. Morrison, I.M. Warner, L.S. Dale, Anal. Chem. 62 (1990) 1637.

7. J. Messerschmidt, F. Alt, G. Tölg, J. Angerer, K. H. Schaller, Fresenius J. Anal. Chem., 343 (1992) 391.

8. F. Alt, A. Bambauer, K. Hoppstock, B. Mergler, G. Tölg, Fresenius J. Anal. Chem., 346 (1993) 693.

9. Ch. Wei, G.M. Morrisson, Anal. Chim. Acta 284 (1994) 587.

10. J. Messerschmidt, F. Alt, G. Tölg, Anal. Chim. Acta 291 (1994) 161.

11. S.B. Adeloju, A.M. Bond, S.N. Tan, G. Wei, Analyst 115 (1990) 1569.

12. M.S. EI-Shahawi, A.Z. Abu Zuhri, M.M. Kamal, Fresenius J. Anal. Chem. 348 (1994) 730.

13. C. Leon, H. Emons, P. Ostapczuk, K. Hoppstock, Anal. Chim. Acta 356 (1997) 99.

14. Z. Zhao, H. Freiser, Anal. Chem. 58 (1986) 1498.

15. M. Georgieva, B. Pihlar, Electroanalysis 8 (1996) 1155.

16. M. Georgieva, Port. Electrochim. Acta 18 (2000) 137.

17. M. Georgieva, Fifth International Symposium and Exhibition on Environmental Contamination in Central and Eastern Europe, Symposium Proceeding, 1780-1784, Prague, 2000.

18. J. Wang, K. Varughese, Anal. Chim. Acta, 199 (1987) 185.

19. C.M.G. van den Berg, J. Electroanal. Chem., 215 (1986) 111.

20. A.J. Bard, L.R. Faulkner, Electrochemical Methods: Fundamentals and Applications, Wiley, New York, 1980, p. 718.

21. E. Laviron, J. Electroanal. Chem., 49 (1974) 355.

22. A.P. Brown, F.C. Anson, Anal. Chem., 49 (1977) 1589.

23. F.A. Cotton, G. Wilkinson, Advanced Inorganic Chemistry, $3^{\text {rd }}$ Ed., pp. 990-1044. Interscience, New York, 1972.

24. A.E. Martell, R.M. Smith, Critical Stability Constants, Vol. 3, Plenum Press, New York, 1977. p.306. 